\title{
Amlodepine induced gingival enlargement - presentation of a clinical case series.
}

\author{
Rashi Chaturvedi ${ }^{1}$, Ashish Jain ${ }^{2}$
}

${ }^{1}$ M.D.S., D.N.B. Reader, Department of Periodontics, Dr. Harvansh Singh Judge Institute of Dental Sciences \& Hospital, Panjab University, Chandigarh, India

${ }^{2}$ Professor \& Head, Department of Periodontics. Dr. Harvansh Singh Judge Institute of Dental Sciences \& Hospital. Panjab University, Chandigarh, India.

\section{Correspondence:}

House. No. 1036,

second floor, sector 40-B

Chandigarh, India

E-mail address: rashichaturvedi@yahoo.co.in

\begin{abstract}
Objectives: Gingival enlargement as an adverse effects of drugs has been found to be long associated with the use of anticonvulsants; phenytoin, anti-hypertensives; calcium channel blockers and immunosuppressants; cyclosporine. Nifedepine was found to cause gingival overgrowth with an incidence ranging from 15-85\%. However, Amlodepine a relatively newer agent of the same group which is being routinely and vastly prescribed either alone or as part of combination therapy to middle to older aged adults has also been found to exhibit this adverse effect with very few cases reported till date. The effect of the dose of amlodepine on the severity of gingival enlargement needs to be assessed.

Study design: A clinical presentation of a series of five cases in the age range of 45-65 yrs with gingival over-growth as a side effect of therapy with amlodepine is presented with prescription of variable doses of $2.5 \mathrm{mg}, 5 \mathrm{mg}$ and 10 $\mathrm{mg}$ per day. A brief review on the pathogenesis of this condition, commonly associated etiological mechanisms and sequence of periodontal therapy rendered have also been included.

Conclusion: Irrespective of the dose of amlodepine administered, gingival enlargement continues to be a predominant side effect in all of the five cases presented. The accentuated gingival contours accumulate plaque leading further to the destruction of the underlying periodontium. Dental professionals need to identify and then guide the patient to seek necessary medical intervention.
\end{abstract}

Key words: Amlodipine, hypertension, gingival enlargement, anti-hypertensives, internal bevel gingivectomy. 


\section{Introduction}

Gingival enlargements are commonly seen as a side effect of various groups of medications which includes: Anticonvulsants, anti-hypertensives; esp. Calcium channel blockers and immunosuppressants. Amlodepine is a third generation dihydropyridine which has been found to be very useful in middle aged to older aged adult patients for various cardiovascular conditions. It functions by inhibiting calcium ion influx across cell membranes of heart and smooth muscles thereby, blocking its intra-cellular mobilization (1). The incidence of gingival enlargement with amlodepine was reported to be much lesser than nifedepine $(2,3)$, however; recently large numbers of cases are being highlighted. Clinically, the enlargement is usually seen 3-6 months following the initiation of the drug in question. The overgrowth of the gums is generally painless and predominantly involves the maxillary and mandibular anterior teeth usually affecting the marginal and inter-dental gingiva (2). When uncomplicated by inflammation the lesion appears firm, pale pink and resilient with a minutely lobulated surface and no tendency to bleed. However, gingival enlargements as a side effect of drugs are usually superimposed with an inflammatory condition due to development of unfavorable gingival contours. The enlarged gingival tissues accumulate plaque and also hinder the maintenance of routine oral hygiene which poses a major problem resulting in the destruction of the underlying bone and attachment loss leading to periodontitis (4). Very few cases of amlodipine induced gingival enlargements have been reported till date (5-7), as a result of which it continues to be vastly prescribed. This presentation of 5 cases attempts to bring to light the existence of this adverse effect with the use of Amlodepine not as a rarity but a routinely observed finding in patients who have been prescribed this drug for various cardiac conditions. The patients discussed were on different doses of amlodipine either alone or in conjunction with other groups of anti-hypertensives. The effect of the dose of amlodipine on the severity of gingival enlargement was also assessed.

\section{Case Series}

All of the five cases presented to the dental office with a similar complaint of generalized swelling in the gums with bleeding and suppuration from them. On evaluating their medical histories all of them were hypertensives and on amlodipine therapy. The first case was of a 45 year old lady who gave a positive history of hypertension and hypothyroidism and was on medication for the same. On exploring further the anti-hypertensive drug identified was amlodipine $10 \mathrm{mg}\left(\right.$ Amlopres $\left.^{\circledR}\right)$ taken daily since last one year and Thyroxine 100 microgram (Thyronorm ${ }^{\circledR}$ ). On clinical examination, a large bulbous enlargement of the gums was seen in relation to left lower lateral inci-

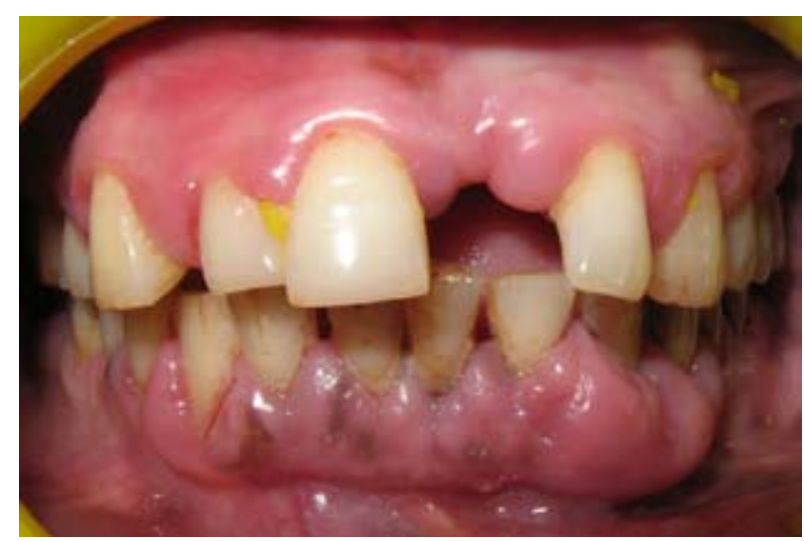

Fig. 1. Photograph showing clinical presentation of Case No.1

sor and canine region. The swelling involved the marginal gingiva, inter-dental papilla as well as the attached gingiva and extended into the vestibule. On examining the rest of the oral cavity, the marginal and inter-dental gingiva of almost all the teeth were enlarged especially in the maxillary and mandibular anterior region with a superimposed inflammatory component. (Fig. 1)

The second case was that of a 60 year old man who presented to the out-patient department with a chief complaint of swelling in the gums in relation to the left lower back tooth region since 6 months. The swelling was painful on mastication and interfered with the placement of the patient's removable prosthesis. Medical history revealed the patient to be hypertensive and was taking amlodipine $5 \mathrm{mg}$ as a single daily dose since 2 yrs. Clinical examination revealed that the marginal and inter-dental papillary gingival tissues were enlarged especially in relation to the upper and lower anterior teeth. The tissues appeared firm and fibrotic with a mulberry appearance on the surface. Additionally, a large bulbous enlarged gingiva around the left lower third molar region extending from the mesial aspect adjoining an edentulous space to the buccal and distal aspect of the third molar was seen. (Fig. 2)

The remaining three cases were on a combination of amlodepine $2.5 \mathrm{mg}$ and atenolol $25 \mathrm{mg}$ once daily since

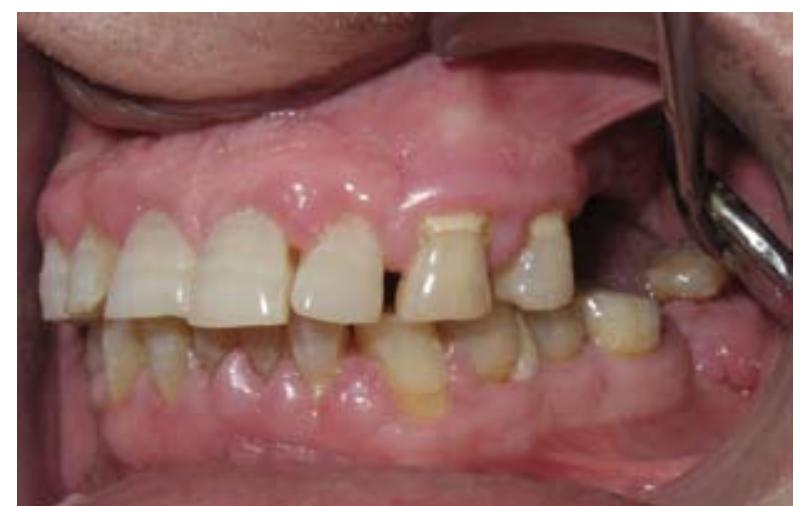

Fig. 2. Photograph showing clinical presentation of Case no. 2 


\begin{tabular}{|c|c|c|c|c|c|c|c|}
\hline $\begin{array}{l}\text { Case } \\
\text { No. }\end{array}$ & Age & Sex & $\begin{array}{l}\text { Treatment } \\
\text { time with } \\
\text { Amlodepine }\end{array}$ & $\begin{array}{l}\text { Dose of } \\
\text { Amlo- } \\
\text { depine }\end{array}$ & $\begin{array}{l}\text { Presence } \\
\text { of other } \\
\text { diseases }\end{array}$ & $\begin{array}{l}\text { Other drugs prescribed } \\
\text { (dose /day) }\end{array}$ & Treatment rendered \\
\hline 1. & $\begin{array}{l}45 \\
\text { yrs }\end{array}$ & Female & One year & $10 \mathrm{mg}$ & $\begin{array}{l}\text { Hypothyroi- } \\
\text { dism }\end{array}$ & $\begin{array}{c}\text { Thyroxin } \\
100 \text { microgram }\end{array}$ & \multirow{5}{*}{$\begin{array}{ll}\text { - } & \text { Plaque control } \\
\text { measures } \\
\text { - } & \text { Oral hygiene } \\
\text { instructions } \\
\text { - } \\
\text { Scaling/ root } \\
\text { planing } \\
\text { - Internal bevel } \\
\text { gingivectomy } \\
\text { with flap surgery } \\
\text { Regular mainte- } \\
\text { nance \& perio- } \\
\text { dic follow up. }\end{array}$} \\
\hline 2. & $\begin{array}{l}60 \\
\text { yrs }\end{array}$ & Male & Two years & $5 \mathrm{mg}$ & Nil & Nil & \\
\hline 3. & $\begin{array}{l}65 \\
\text { yrs }\end{array}$ & Female & Five years & $2.5 \mathrm{mg}$ & $\begin{array}{ll}\text { - } & \text { Type II } \\
& \text { Diabetes } \\
\text { Mellitus } \\
\text { - } & \text { Angina }\end{array}$ & $\begin{array}{ll}\text { - } & \text { Atenolol 25mg } \\
\text { - } & \text { Metformin } 1000 \mathrm{mg} \\
\text { - } & \text { Ecosprin } 75 \mathrm{mg} \\
\text { - } & \text { Atorvastatin }\end{array}$ & \\
\hline 4 & $\begin{array}{l}45 \\
\text { yrs }\end{array}$ & Female & Two years & $2.5 \mathrm{mg}$ & Nil & Nil & \\
\hline 5. & $\begin{array}{l}55 \\
\text { yrs }\end{array}$ & Female & Three years & $2.5 \mathrm{mg}$ & Nil & Nil & \\
\hline
\end{tabular}

Table 1. Details of the demographics, medical history and treatment of the clinical cases

2-3 years. The first of these cases was additionally diabetic and also gave a history of angina 3 years back. This patient had been prescribed various drugs due to the prevailing cardiac condition. The other two cases were only hypertensive with no other systemic complicating factors. Clinical evaluation revealed diffuse gingival overgrowth especially in relation to upper and lower anterior teeth, and also involving the marginal and inter-dental papilla of the posterior regions. Bleeding on probing and suppuration were elicited with presence of copious plaque and calculus deposits. (Fig. 3a) The clinical details of the cases have been tabulated. (Table 1)

Based on clinical evaluation and radiographic assessment a provisional diagnosis of amlodepine induced drug enlargement superimposed with inflammation was established. Phase-I periodontal therapy comprising mechanical and chemical removal of plaque and calculus as well as patient instructions on oral hygiene maintenance was initiated. The patient was simultaneously advised to seek medical consultation. Following oral prophylaxis and substitution of amlodipine, significant improvement in the gingival tissues was observed (Fig. 3b). However, the OPG X-rays of these patients revealed the presence of generalized underlying bone loss. The gingival contours were un-esthetic, difficult to maintain and favored plaque accumulation leading to further destruction of the attachment apparatus. Hence, phase II periodontal therapy was performed with an internal bevel gingivectomy and flap operation. The tissues excised were duly sent for histo-pathological assessment which revealed the presence of parakeratinized epithelium with acanthosis and elongated rete-pegs, connective tissue fibrosis with inflammatory cells, few scattered giant cells and capillaries indicating a superimposed inflammation. This further confirmed our diagnosis of drug associated gin- gival enlargement. Post-operative evaluations revealed that good physiological contours for the patient had been achieved favoring good plaque control.

\section{Discussion}

Calcium channel blockers comprise of three chemical
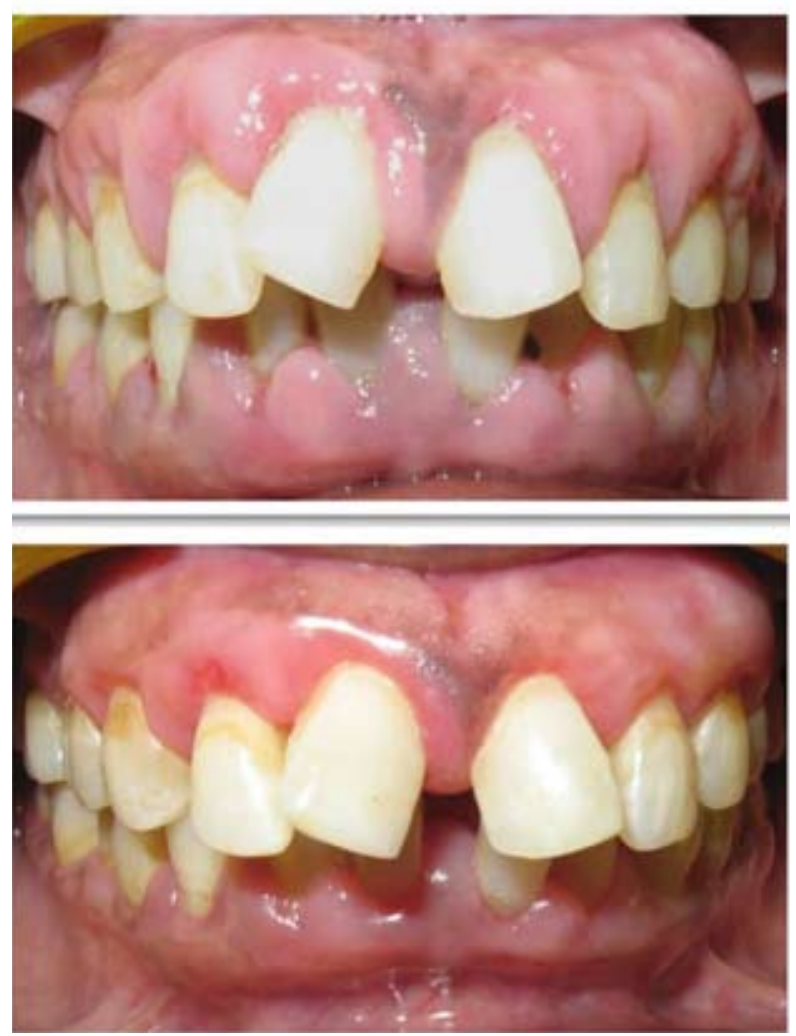

Figure 3. A. Photograph showing clinical presentation of Case no. 3 B. Photograph showing Case No. 3 two months following amlodipine substitution and phase I therapy. 
families viz. dihydropyridines including nifedepine, amlodipine, felodipine etc., phenylalkylamines which includes verapamil and benzothiazepines which includes diltiazem. Compared to conventional therapy (diuretics and beta blockers), calcium channel blockers have been found to be more effective and hence these are more frequently prescribed (1). The dihydropyridines have been found to be associated with enlargement of the gums with nifedepine having the highest incidence of about $6 \%$ (3). Amlodipine however is also being found to be associated with gingival overgrowth and more and more such cases are being reported. A recent study comparing the effect of calcium channel blockers vis-à-vis Renin angiotensin system drugs showed a twofold greater enlargement of the gums with the current use of the former category of drugs. This association was dose dependant and greatest for dihydropyridine derivatives (8). In the case series presented, different doses of amlodepine did not correlate with the severity of the clinical presentation.

The underlying mechanism for the pathogenesis of this gingival over-growth remains to be fully understood. These drugs which affect intracellular calcium metabolism or transport may in some patients stimulate gingival fibroblasts to cause increased deposition of extracellular matrix components, such as glycosaminoglycans (2). The other proposed non-inflammatory mechanisms include defective collagenase activity, blockage of aldosterone synthesis in adrenal cortex which is also calcium dependent and causes a consequent feedback increase in ACTH level (9), and up-regulation of the keratinocyte growth factor (10). Alterations in the cytokine balances may contribute more significantly to the development and maintenance of gingival overgrowth. Proliferation and differentiation of connective tissue cells and production of extracellular matrix are controlled by cytokines that initiate signaling cascades mediated by specific receptors. Recent studies have demonstrated abnormally high levels of specific cytokines such as IL-6, IL-1beta, platelet derived growth factor (PDGF-B), Fibroblast growth factor (FGF-2), Transforming growth factor (TGF-beta) and connective tissue growth factor (CTGF) in gingival overgrowth tissues (11).

Drug induced gingival enlargements are usually associated with a superimposed inflammatory component which has to be minimized as it is a major contributor to the gingival overgrowth (12). Scrupulous oral hygiene maintenance by effective plaque control strategies both home care and professional need to be taken care of. This helps in decreasing the degree of gingival overgrowth present, improves overall gingival health and helps maintain attachment levels. In cases with severe gingival overgrowth one needs to consider the substitution of amlodipine with isradipine, lercanidipine and lacidipine which are the newer fourth generation dihydro- pyridines or other classes of anti-hypertensives such as beta blockers, A.C.E inhibitors or thiazide derivatives. Discontinuing the causative drug has been found to reduce the gingival overgrowth (13), however, to assist the patient in plaque control as well as from an esthetic point of view surgical correction may be deemed necessary. Cases in which there is no underlying bone loss, external bevel gingivectomy and gingivoplasty is done. In cases with presence of attachment loss and underlying osseous defects, a procedure called internal bevel gingivectomy with flap operation is performed so as to be able to resect the gingival overgrowth and in addition treat the underlying osseous defects $(12,14)$. All of the five cases that are presented had some degree of moderate to severe alveolar bone loss and hence internal bevel gingivectomy was the treatment of our choice. The patients were followed up for a period of up-to one year and with drug substitution and plaque control, no recurrences were seen. On clinical assessment, the effect of amlodipine on gingival tissues was probably not dose related because even $2.5 \mathrm{mg}$ of amlodepine had resulted in a significant gingival enlargement. This probably contradicts Jorgenson's study on cardiac patients taking amlodipine at a dose of $5 \mathrm{mg} /$ day and showing no incidence of gingival overgrowth (15). Importance of plaque control needs a special emphasis here as it could be a major contributing factor for accentuating the enlargement even at low serum levels of amlodipine.

\section{Conclusions}

One needs to abreast this issue to the various medicine experts to bring this fact to light and to minimize the prescriptions or practice care while prescribing the innocuous appearing Amlodepine. Even with minimal dose of amlodepine a significant gingival enlargement is seen hence, regular follow up with suitable dental referral for evaluating gingival and periodontal status becomes imminent. Dental professionals need to identify and then guide the patient to seek necessary medical intervention.

\section{References}

1. Levine CB, Fahrbach KR, Frame D, Connelly JE, Estok RP, Stone LR et al. Effect of amlodipine on systolic blood pressure. Clin Ther. 2003; 25: 35-57.

2. Dongari-Bagtzoglou A; Research, Science and Therapy Committee, American Academy of Periodontology. Drug associated gingival enlargement. J Periodontol. 2004; 75: 1424-31.

3. Ellis JS, Seymour RA, Steele JG, Robertson P, Butler TJ, Thomason JM. Prevalence of gingival overgrowth induced by calcium channel blockers: A community based study. J Periodontol. 1999; 70: 63-7.

4. Hassell TM, Hefti AF. Drug induced gingival overgrowth: Old problem, new problem. Crit Rev Oral Biol Med. 1991; 2:103-37.

5. Triveni MG, Rudrakshi C, Mehta DS. Amlodipine-induced gingival overgrowth. J Indian Soc Periodontol. 2009; 13: 160-3.

6. Lafzi A, Farahani RMZ, Shoja MAM. Amlodipine-induced gingival hyperplasia. Med Oral Patol Oral Cir Bucal. 2006; 11:E480-2.

7. Seymour RA, Ellis JS, Thomason JM, Monkman S, Idle JR: Amlo- 
dipine induced gingival overgrowth. J Clin Periodontol. 1994; 21: 281-3.

8. Kaur, G., Verhamme, K. M. C., Dieleman, J. P., Vanrolleghem, A., Van Soest, E. M., Stricker, B. H. C.et al. Association between calcium channel blockers and gingival hyperplasia. J Clin Periodontol. 2010; 37: 625-30

9. Nyska A, Shemesh M, Tal H, Dayan D. Gingival hyperplasia induced by calcium channel blockers: mode of action. Med Hypotheses. 1994; 43: 115-8.

10. Das SJ, Olsen I. Keratinocyte growth factor is upregulated by hyperplasia-inducing drug nifedipine. Cytokine. 2000; 12:1566-9.

11. Trackman P.C., Kantarci A. Connective tissue metabolism and gingival overgrowth. Crit Rev Oral Biol Med. 2004; 15: 165-75.

12. Seymour RA. Effects of medications on the periodontal tissues in health and disease. Periodontol 2000. 2006; 40: 120-9.

13. Westbrook P, Bednarczyk EM, Carlson M, Sheehan H, Bissada NF. Regression of nifedepine Induced gingival hyperplasia following switch to a same class calcium channel blocker, Isradipine. J Periodontol. 1997; 68: 645-50.

14. Camargo PM, Melnick PR, Pirih F R Q, Lagos R, Takei H.H. Treatment of drug-induced gingival enlargement: aesthetic and functional considerations. Periodontol 2000. 2001; 27: 131-8.

15. Jorgensen MG. Prevalence of Amlodipine-related gingival hyperplasia. J Periodontol. 1997; 68: 676-8. 